Annals of Plant and Soil Research 23(2): 181-185 (2021)

https://doi.org/10.47815/apsr.2021.10053

\title{
Charcterization of a medicinal plant Agastya (Sesbania grandiflora)
}

\author{
NEENA BAGCHI*, SANTOSH K SAR ${ }^{1}$ AND AMIT SHARMA \\ Department of Botany, Dr. C.V. Raman University, Kota, BILASPUR (CG) 495113
}

Received: February, 2021; Received: accepted, March, 2021

\begin{abstract}
The chemical characterization of the leaves of Sesbania grandiflora were carried out in a quest to evaluate its bioactive potential to cure diseases and its potential as a source of alternate medicine. Fresh leaves of S. grandiflora were collected and powdered for analysis. The proximate analysis of the leaves showed that the proportion of moisture content, volatile matter, ash content and fixed carbon were $5.16 \%, 67.4 \%$, $17.64 \%, 9.8 \%$ respectively. The results of FTIR revealed the strong bonds between $C-H, C-O, C=O, C=C, S=O$ and $\mathrm{N}-\mathrm{H}$ in the plant material. Moreover the result of TGA depicts that the highest weight loss occurred at temperature of $486.64^{\circ} \mathrm{C}$ with a degradation rate of $10.00 \mathrm{~K} / \mathrm{min}$ in combustion conditions.
\end{abstract}

Keywords: Sesbania grandiflora, Proximate Analysis, FTIR, TGA, medicinal plant

\section{INTRODUCTION}

Medicinal plants have been used in traditional treatments for numerous human diseases for thousands of years and they continue to be a therapeutic aid even in modern era. Due to the advancement in scientific approach and instrumental analysis, the herbal medicines have come in light and People are taking more interest in traditional medicine. As a result there is an increase in demand for more drugs from plant sources. The development of pharmaceutical sectors, new therapeutics and improvement of health issues have been observed in the human history only due to the identification and isolation of biologically active compound and molecules from plants. (Pye et al. 2017). Treatment of patients and development of medicine is the objective of ethno pharmacology and ultimately the verification of the folklore practices of medicinal plants. (Anand et al. 2019). The main objective of this study is the characterization of a medicinally important plant Agastya (Sesbania grandiflora L.) of family Fabaceae so that it may become pharmacologically important and confirm all medicinal practices used by earlier studies. It may be also helpful for further study.

Sesbania grandiflora commonly known as Agastya is a small tree with loose branching which grows up to 6-9 m height and its diameter is about $25-30 \mathrm{~cm}$. Flowers are white and fleshy, they are 7.5 to $10 \mathrm{~cm}$ long and pea like, found in clusters hanging at leaf base. The leaves are 5 to 30 centimeters long and pinnate having 16 to 30 pairs of leaflets, which are 2.5 to 3.5 centimeters long. (Mahadik et al. 2018). The leaves turn yellow before shedding. Fruits are long and thin green beans containing 28-30 seeds. Flowering and fruiting is almost throughout the year but mostly its season is winter. Cultivation of Sesbania grandiflora is done in India, Indonesia, Malaysia, Philippine and Myanmar. It is extremely fast growing important agro forestry species for food, fodder, forage, paper and pulp which thrives even in nutrient deficient soils as this plant has high affinity for association with nitrogen fixing Rhizobia. Phytochemical constituents, that are present in the leaves of Sesbania grandiflora, are alkaloid, flavanoids, glycosides, tannins, steroids, proteins, carbohydrates, saponins, amino glycoside, Vitamin A, C \& B complex, Glycoside, Coumarines. (Mahadik et al. 2018). Due to the presence of these phytochemicals, it is antihelmenthic, antiulcer, antibacterial and shows antioxidant activity. In addition, ethanolic extract of leaf shows antihypertensive activity, methanolic extract shows analgesic and CNS depressant activity and aqueous extract shows antiurotithiatic and antioxidant activity. (Mahadik et al. 2018). The whole plant of Sesbania grandiflora is used for curing microbial infections, inflammation, dysentery and diarrhea. (Arfan 2016). Therefore an investigation was carried out to characterize the Sesbania grandiflora leaves for their biochemical constituents. 


\section{MATERIALS AND METHODS}

Leaves of Sesbania grandiflora were collected from Durg district of Chhattisgarh in the month of May-June 2020. Chhattisgarh is located in the central part of India. The geographical location is $17^{\circ} 46^{\prime} \mathrm{N}$ to $24^{\circ} 5^{\prime} \mathrm{N}$ latitude and from $80^{\circ} 15^{\prime} \mathrm{E}$ to $84^{\circ} 20^{\prime} \mathrm{E}$ longitude. Climate and weather condition of the state is mainly dry and hot. During summer season the temperature varies from $42^{\circ} \mathrm{C}$ to $45^{\circ} \mathrm{C}$. During winter, temperature falls down. The soil of Chhattisgarh is mainly known by its red color and the vegetation of this state is very rich where forest area covers about 44 percent.

Leaf samples of three healthy plants of Sesbania grandiflora were collected, which were washed and dried in shade. The dried leaves were grinded in electric grinder to get a fine powder. It was then sieved to get 105 micron size particle for further use. This was followed by storing it in air tight bottles. Proximate analysis was done as per methods of Kathiresan Prabhu et al. (2011). Moisture was determined by heating a known quantity of dried sample to 105$110^{\circ} \mathrm{C}$ for one hour and percentage was calculated by the loss in weight. About $1 \mathrm{~g}$ of sample was heated in a silica crucible for 7 minutes at a steady temperature of $625^{\circ} \mathrm{C}$ in a muffle furnace to get the volatile matter. Sample of about $1 \mathrm{~g}$ was dried at $100-105^{\circ} \mathrm{C}$ for one hour and ignited in a muffle at $600-625^{\circ} \mathrm{C}$ until ash was formed which was carbon free. A carbon free ash remains as residue and is weighed. In FTIR: In this technique, infrared light is used to scan the test sample to identify the chemical bonds present in a molecule. Functional group present in the medicinal plant sample is confirmed by comparing the absorption bands with the peaks obtained (Nair et al. 2013). With the help of Thermo gravimetric analysis, thermal stability of materials can be known, the mechanism of decomposition and rate of reaction could be understood. It was done with the help of Module: TGA 1 SF/1100 /321,02.11.2015 13:58:28. Method: 25-600@ $10 \mathrm{~N} 240 \mathrm{ml}$ dt $1.00 \mathrm{~s}$ [1] $25.0 . .600 .0^{\circ} \mathrm{C}, 10.00 \mathrm{~K}$ /min, $\mathrm{N}_{2} 40.0 \mathrm{ml} / \mathrm{min}$. Synchronization enabled.

\section{RESULTS AND DISCUSSION}

The Proximate composition of Sesbania grandiflora (Table 1) indicated that the ash content was high (17.64\%) in the leaves of Sesbania grandiflora. Leaves had low moisture content of $5.16 \%$, high content of volatile mater (67.4\%) and carbon (9.8 per cent). An inorganic residue ash, remained after the removal of water and organic matter by heating gave total amount of minerals within the food. As the minerals have low volatility as compared to other food components, they are not destroyed by heating and these ashes provided an idea of mineral matter present in the parts of the plants. Similar result of ash percentage was reported by Veerabhadrappa (2017). Determining the ash content is a part of proximate analysis for the evaluation of nutrition and an important quality attribute for variety of food products. (Ismail 2017). The leaf of Sesbania grandiflora contained $\mathrm{Ca}, \mathrm{P}, \mathrm{Fe}, \mathrm{Na}, \mathrm{K}$, ascorbic acid, $\beta$ carotene. (Veerabhadrappa 2017). It is a known fact that metals and minerals in the permissible level play very important role in the biological system of plants and animals.

Table 1: Proximate composition of Sesbania grandiflora

\begin{tabular}{|l|c|c|}
\hline Proximate composition & Range & Mean \\
\hline Moisture Content\% & $0-70 \%$ & $5.16 \%$ \\
Volatile Matter\% & $0-90 \%$ & $67.4 \%$ \\
Ash\% & $0-20 \%$ & $17.64 \%$ \\
Carbon\% & $0-25 \%$ & $9.8 \%$ \\
\hline
\end{tabular}

Flavonoid and alkaloid were highly present in leaves (Table 2). The moderate amount of saponin and terpenoid was identified in the leaves. The presence of tannin and anthocyanin was also recorded. On the other hand, good amounts of carbohydrate and proteins were noted in leaves of Sesbania grandiflora. Similar results were reported by Mohiuddin (2019) and Mashhadi (2020). Due to the presence of immense amount of calcium it reduces the risk of osteoporosis and arthritis in older people. Due to the presence of these bioactive constituents, Sesbania grandiflora leaves have potential antidiabetic activities and provide scientific rationale for its use in the traditional system of medicine. This corroborates the finding of Sangeetha et al. (2014). 
Table 2: Phytochemical Analysis of Sesbania grandiflora

\begin{tabular}{|c|c|}
\hline Phytochemical & Status \\
\hline Alkaloid & + \\
Flavonoid & ++ \\
Saponin & + \\
Terpenoid & + \\
Glycoside & + \\
Tannin & + \\
Anthraquinone & + \\
Phytobatannins & + \\
Steroid & + \\
Carbohydrate & + \\
Protein & ++ \\
\hline
\end{tabular}

\section{Fourier Transform Infrared Spectroscopy}

Fourier Transform Infra red spectroscopy of the sample was conducted to determine the presence of functional group and to understand the significance of presence of particular bioactive component. The values of peaks and functional groups were depicted in Fig,1. The presence of functional group like alkanes, aldehyde, amine, alkane, sulfoxide, alkenes and Halo compounds in the leaves of Sesbania grandiflora were confirmed by the more intense absorption band occurring at 2916.16, 2848.52, 1723.17, 1589.17, 1382.49, 1058.32, 815.87, 708.97 and $629.57 \mathrm{~cm}-1$ corresponding to $\mathrm{C}-\mathrm{H}$, $\mathrm{C}-\mathrm{H}, \mathrm{C}=\mathrm{O}, \mathrm{N}-\mathrm{H}, \mathrm{C}-\mathrm{H}, \mathrm{S}=\mathrm{O}, \mathrm{C}=\mathrm{C}, \mathrm{C}=\mathrm{C}$ and $\mathrm{C}-\mathrm{Br}$ stretching, bending, vibrations respectively.

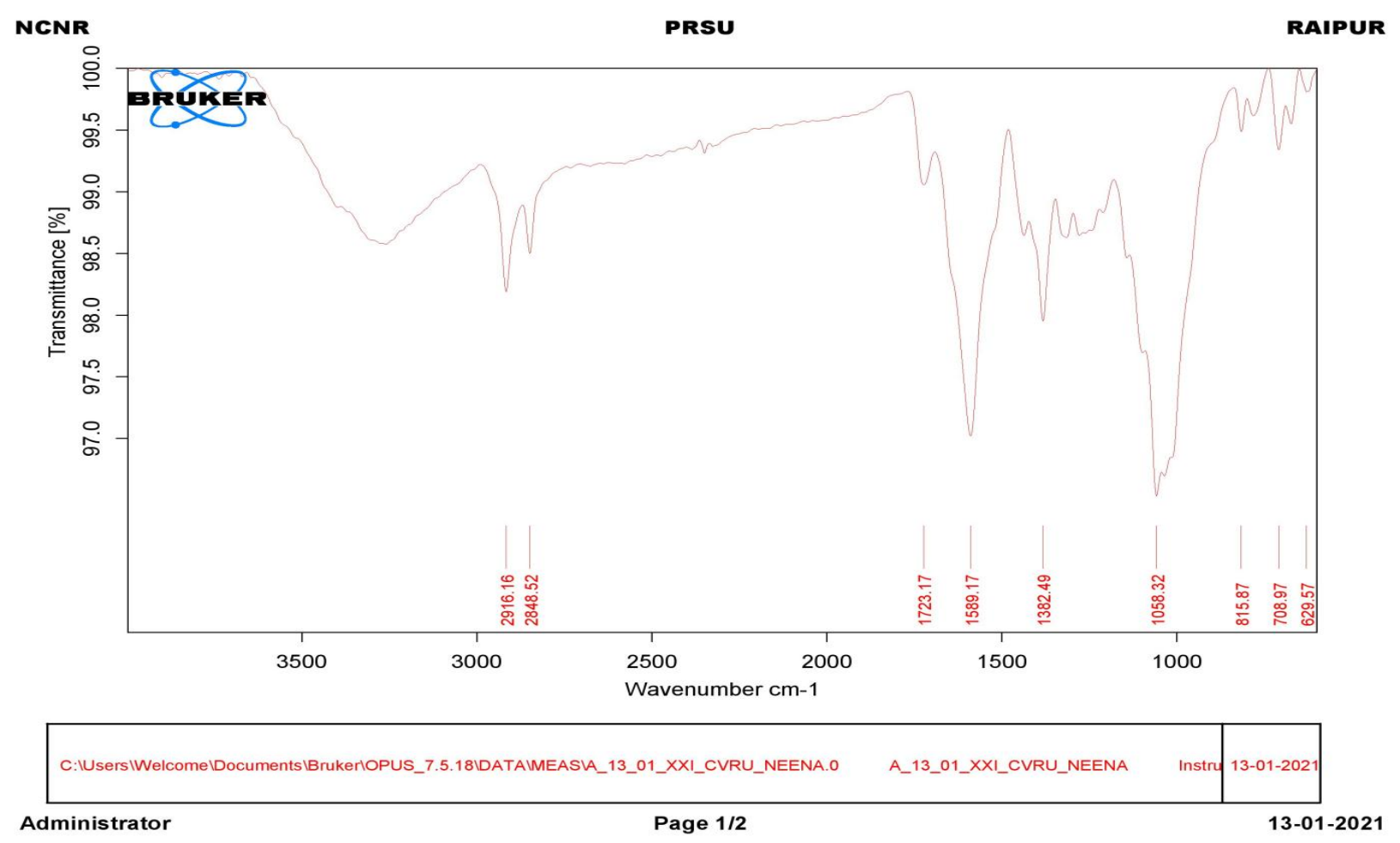

Fig.1: FTIR of Sesbania grandiflora (leaf)

Presence of alkane was confirmed by the strong absorption band observed between 3000-2840 at 2848.52 and $2916.16 \mathrm{~cm}-1$. Presence of aldehyde $\mathrm{C}=\mathrm{O}$ was confirmed by the strong stretching band observed between $1740-1720$ at $1723.17 \mathrm{~cm}^{-1}$. Presence of amine was confirmed by the $\mathrm{N}-\mathrm{H}$ bending between $1580-1650$ at $1589.17 \mathrm{~cm}^{-1}$. Presence of alkane can be confirmed by the $\mathrm{C}-\mathrm{H}$ bending at 1382.49 between 1385-1382. Presence of sulfoxide was confirmed by $\mathrm{S}=\mathrm{O}$ stretching band observed between 1070-1030 at $1058.32 \mathrm{~cm}^{-1}$. Presence of alkene was confirmed by the $\mathrm{C}=\mathrm{C}$ bending between $790-840$ at 815.87 and $690-665$ at $708.97 \mathrm{~cm}^{-1}$. Halo compound of $\mathrm{C}-\mathrm{Br}$ stretching can be observed between $690-515$ at $629.57 \mathrm{~cm}^{-}$ 1. 
Functional groups play an important role in the formation of biological molecules such as protein, DNA, carbohydrates and lipids. Amino acids and amines are important constituents of protein synthesis and play a vital role in the physiology of living organism. An example of sulfoxide occurring in nature is alliin which is also found in garlic that have much ayurvedic importance. Sulphur derivative compounds were used to prepare disinfectants and dermal cream. (Nair et al. 2013). Functional groups are important components of drug molecule. From the medicinal chemistry perspective, these functional groups provide the specific properties and behaviour that allow the drug molecule to show their pharmacokinetic and pharmacodynamic effects. (Herrold and Zavod 2017).

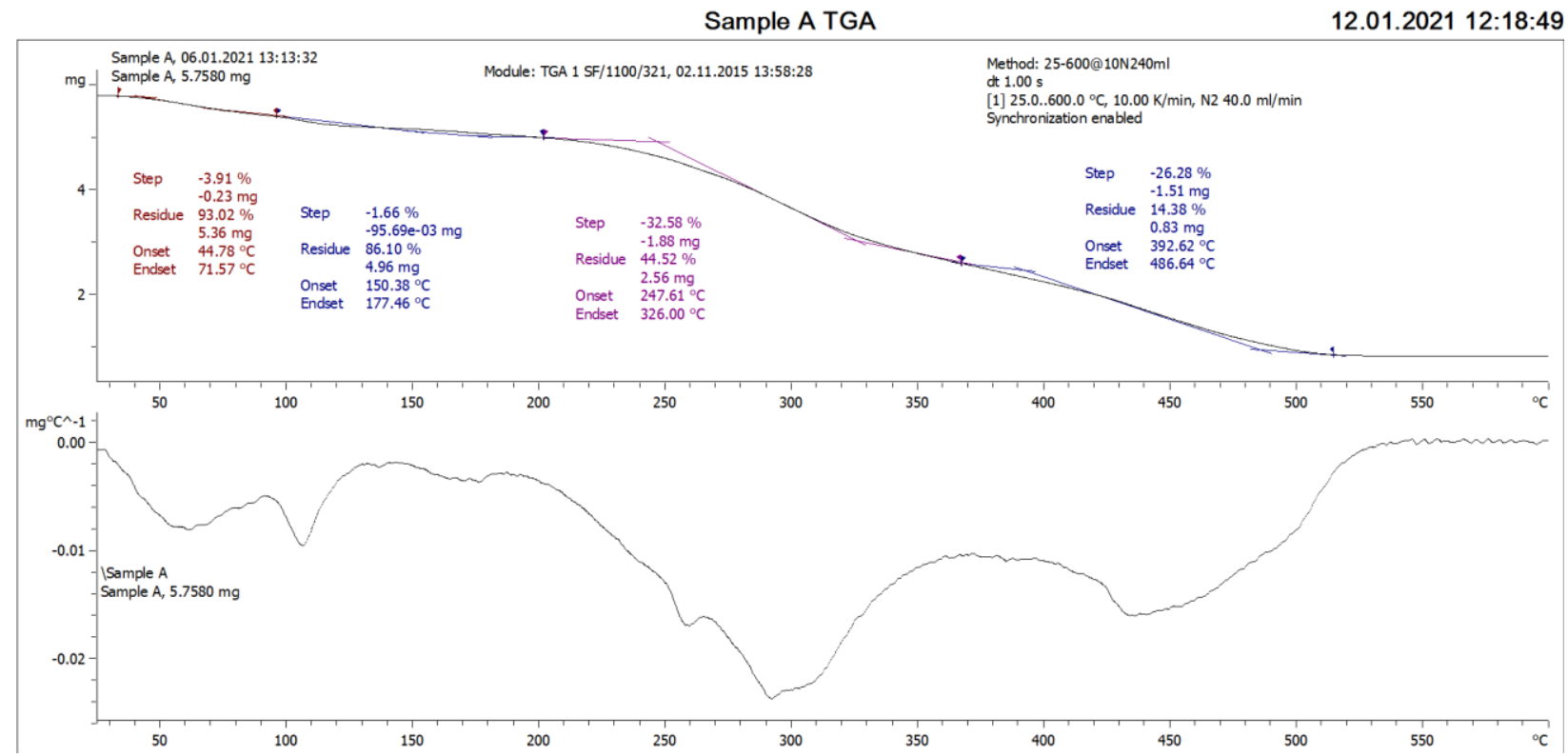

Fig. 2: Plot between weight and temperature of_Sesbania grandiflo

\section{Thermo gravimetric analysis of leaves}

The leaves of Sesbania grandiflora were subjected to Thermo gravimetric analysis. A descending $Z$ shaped curve was obtained from TGA curve. It depicts the weight of the sample in four stages. In TGA graph the initial decomposition of the biomass occurred at onset temperature of $44.78{ }^{\circ} \mathrm{C}$ to eliminate the moisture content and the volatile matter present in the biomass and its end set is $71.57^{\circ} \mathrm{C}$. In this first step $93.02 \%$ of residue remains and loss of $0.398 \mathrm{mg}$ of biomass occurred. In the second step $0.4 \mathrm{mg}$ of biomass has decomposed and $86.10 \%$ of residue remains in which onset temperature is $150.38{ }^{\circ} \mathrm{C}$ and endset temperature is $177.46{ }^{\circ} \mathrm{C}$. In the third step the highest decomposition of $2.4 \mathrm{mg}$ of biomass that is the carbon content has occurred between onset $247.61{ }^{\circ} \mathrm{C}$ and endset $326^{\circ} \mathrm{C}$ in which residue is $44.52 \%$. In the fourth step $1.7 \mathrm{mg}$ of biomass has decomposed at onset $392.62^{\circ} \mathrm{C}$ and endset $486.64{ }^{\circ} \mathrm{C}$ in which $14.38 \%$ residue remains. After that the remaining is the ash component. The curve of weight loss gives information about the thermal stability of the sample, changes in the sample composition and kinetic parameters for chemical reaction. Also it is useful for quality control and identification. Moreover the estimated lifetime, oxidative stability, decomposition and rate of reaction could be understood. Weight loss of the sample at the initial stage is due to loss of moisture. As the temperature increases further the loss of weight of the sample is due to the decomposition of organic matter and polymer decomposition. The most apparent point of weight loss of the sample can be done with the help of a derivative weight loss curve.

The presence of phytochemicals directly influences the quality of secondary metabolites. They can also serve as active constituents of herbal medicines and may be useful in the treatment of various diseases in future. Proximate analysis is helpful for identification of genuineness which plays key role in 
authentication of plant. They can be used for health care needs to prepare medicines. Ash value shows the qualitative standards, purity and authenticity of the sample. Higher ash value shows higher mineral content and lower value of moisture and high carbon content shows high calorific value in the leaves of $S$. grandiflora. FTIR spectrum was used to identify the functional group of the active component and due to the presence of this particular functional group it may be helpful for the treatment of disease. With the help of analysis of TGA,

\section{REFRENCES}

Anand, Utpal., Nadia. Jacobo-Herrera., Altemimi, A. and Lakhssassi, N. (2019) A Comprehensive Review on Medicinal Plants as Antimicrobial Therapeutics: Potential Avenues of Biocompatible Drug Discovery. Southern Illinois University Carbondale .9(11): 258.

Arfan, N. B., Julie, A.S., Mohiuddin, A. K., Khan, S.A., Labu, Z. K. (2016) Medicinal properties of the Sesbania grandiflora leaves. Ibnosine Journal of Medicine and Biomedical Sciences. 8(6): 271-277.

Harrold, M. W., Zavod, R. M (2018) Basic concepts in medicinal chemistry. Edition 2 :Chapter- 2, American Society of Health-System Pharmacists:21-66.

Ismail, Baraem P. (2017) Book: Food Analysis Laboratory Manual. Chapter: Ash Content Determination. Springer 117-119 DOI: 10.1007/978-3-319-44127-6 11.

Kathiresan, Prabhu., Kakar, P.K., Shiva, Hemlata., Kathiresan, P and Ghatuary, S. $K$ (2011) A comparative study on proximate analysis conducted on three Viburnum Linn.Species. DEr Pharmacia Sinica 2(3): 200-206.

Mahadik, Vaishali J., Patil K. M and Wadkar, Kiran. A. (2017) Sesbania grandiflora (Agastya): A Review on its phytochemical \& pharmacological profile. International Journal of Biological \& pharmaceuticle Rsearch 2017 9(1):1-6. thermal stability of the plant, oxidation, moisture and volatiles content of materials, loss of moisture, drying, corrosion and desorption of the material could be studied which are pharmacologically important.

It may be concluded from the results that sesbania grandifora has potential ant diabetic activities and the result scientifically justifies their use in the folklore remedies. However, further studies are required to identify the bioactive compound responsible for the antidiabetic property of the plant sp.

Mashhadi, Akbar, Boojar M. (2020) An Overview of the Cellular Mechanisms of Flavonoids Radioprotective Effects. Advance Pharmaceutical Bull. 10(1): 13-19.

Mohiuddin, A. K. (2019) Medicinal and Therapeutic values of Sesbania grandiflora. Journal of Pharmacology and Clinical trials 2019 (1) Short Communication.

Nair, L. D., Sar, S. K., Arora, A. and Mahapatra, D. (2013) Fouirier Transform Infrared Spectroscopy Analysis of Few medicinal Plants of Chhattisgarh, India. Journal of Advance Pharmacy Education \& Research 3 (3):196-200.

Pye, C.R., Bertin, Lokey, J.M., Gerwick, S.R., Linington, R.G. and Retrospec H. W. (2017) Retrospective analysis of natural products provides insights for future discovery trends. Proc. Natl. Acad. Sci. USA 114, 5601-5606.

Sangeetha, A., Prasath, G. S. and Subramanian, S. (2014) Antihyperglycemic and antioxdant potentials of S.Grandiflora leaves studied in STZ induced experiment diabetic rats. International Journal of Pharmaceuticle Science and Research 5: 2266-2275.

Veerabbhadrappa, K. V. and Reddy, J. R. (2017) Microscopical Evaluation \& Proximate Analysis Sesbania grandiflora A folk Lore Plant. . Coden IJABFP-CAS-USA. 8 (2): 15-21. 